\title{
Cost-benefit analysis of the ATM automatic deposit service
}

\author{
Ivica Županović 1,*$^{*}$ Marko Hell ${ }^{2}$ and Dino Pavlić ${ }^{2}$ \\ ${ }^{1}$ Splitska banka Societe Generale Group \\ Ruđera Boškovića 16, 21000 Split, Croatia \\ E-mail: 〈ivica.zupanovic@splitskabanka.hr〉 \\ ${ }^{2}$ Faculty of Economics, University of Split \\ Cvite Fiskovića 5, 21000 Split, Croatia \\ E-mail: 〈\{marko.hell, dino.pavlic\}@efst.hr〉
}

\begin{abstract}
Bankers and other financial experts have analyzed the value of automated teller machines (ATM) in terms of growing consumer demand, rising costs of technology development, decreasing profitability and market share. This paper presents a step-bystep cost-benefit analysis of the ATM automatic deposit service. The first step is to determine user attitudes towards using ATM automatic deposit service by using the Technology Acceptance Model (TAM). The second step is to determine location priorities for ATMs that provide automatic deposit services using the Analytic Hierarchy Process (AHP) model. The results of the previous steps enable a highly efficient application of cost-benefit analysis for evaluating costs and benefits of automatic deposit services. To understand fully the proposed procedure outside of theoretical terms, a realworld application of a case study is conducted.
\end{abstract}

Key words: automatic deposit service, ATM, Technology Acceptance Model, Analytic Hierarchy Process, cost-benefit analysis

Received: September 23, 2014; accepted: March 18, 2015; available online: March 30, 2015

DOI: $10.17535 /$ crorr. 2015.0020

\section{Introduction}

Today, with the availability of numerous new technologies banks are able to offer new services to their customers. One of such services is the automatic deposit service provided by Automated Teller Machines (ATMs) [27]. The automatic deposit service entails depositing funds into an account where bank notes are placed into an ATM while the money counter recognizes the banknotes. After validation, the approved amount is automatically credited to account. According to the research conducted by RBR, the automatic deposit service is the fastest growing banking technology [13]. The expectation is that

${ }^{*}$ Corresponding author. 
by 2018, the number of installed ATMs providing the automatic deposit service will total 670,000 [14]. NCR, one of the largest manufacturers of ATMs worldwide, has predicted that traditional envelop-based deposits will disappear from the market by 2019 [25]. Other research conducted in the U.S. indicates that the use of the automated deposit service has resulted in some financial institutions in the United States increasing the number of deposit transactions at ATMs by up to $50 \%$ within the first six months of introducing the service [14].

One of the reasons for the rapid development and implementation of automatic deposit services is its lower cost. Making deposits at the counter or at the ATM using envelopes costs $\$ 1.82$ according to the Tower Group, whereas the same transaction for the automatic deposit services at an ATM costs 58 cents, meaning a difference of $\$ 1.24$ [14]. In addition, financial institutions believe that introducing the new service has improved customer relationships due to greater convenience and accessibility and which has ultimately led to greater customer satisfaction and greater satisfaction for financial institutions.

\section{Research overview}

Bankers and financial experts have analyzed the value provided by ATMs. The research has focused particularly on the growing demands of clients, along with the rising costs of technology development and a decline in profitability in relation to the changes in the market share.

According to the research conducted by RBR, the number of installed ATMs in 2013 totaled 2.5 million. The increase in number of ATMs is expected to slow down in North America and Western Europe while in the CEE and M\&A it will continue to rise by $10 \%$ a year [16]. However, according to this research, there has been a global downward trend in newly installed ATMs. Increasing the efficiency of ATM positioning requires a more detailed analysis of user preferences and offered information technology services [17].

The financial effectiveness of ATMs can be increased by bringing investments into line with into line the requirements of potential users of automated deposit services. This trend imposes the logical need to analyze site selection based on user trends.

This paper suggests optimizing the financial performance of financial institutions in line with user preferences and ATMs positioning for providing automatic deposit services using a combination of methods. The model for determining the efficiency of automatic deposit services can be divided into three main steps as shown in Figure 1. 

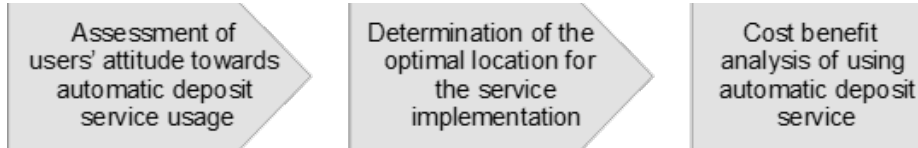

Figure 1: The main steps for determining efficiency of automatic deposit services

\subsection{Assessment of users' attitude towards automatic deposit service usage}

The management at financial institutions has to identify primarily the ultimate beneficiaries, their behavior and the factors that influence adoption of new financial services. In the course of time, a number of methods identifying factors that influence user behavior have been developed [2]. The Technology Acceptance Model (TAM) will be used to evaluate user behavior regarding this matter. This model was developed by Davis in 1989 [12] and was built on the Theory of Reasoned Action (TRA) developed by Fishbein and Ajzen in 1975 [19]. As a model researching the adoption of new technologies, TAM has been widely accepted for predicting the usage of new technologies, including the financial services industry $[2,4,7,9,22,23,15]$. One of the most important general findings of TAM has been perceived ease of use and perceived usefulness which has influenced significantly behavioral intention [10]. Davis [12] defines perceived ease of use as a user's subjective perception that using a certain system will not require significant mental or physical effort. In 2004, Money and Turner [24] also found that a majority of users would prefer to use a system that is easy to use, rather than a useful system. This means that when discussing complicated systems, their performance benefits will be less significant than the difficulties that they pose.

Perceived usefulness are the advantages that using a certain system brings to its users. Davis [12] defined it as a measure referring to individual beliefs that using a particular system would improve and increase overall performance. In 1982, Bandura [6] identified this construct as an extension of self-efficiency in which operations are associated with valued outcomes.

The core TAM models required the formation of research hypotheses. The research hypotheses are as follows:

H1: Perceived ease of use is positively correlated to the perceived usefulness.

H2: Perceived ease of use is positively correlated to the behavioral usage intention.

H3: Perceived usefulness is positively correlated to the behavioral usage intention. 


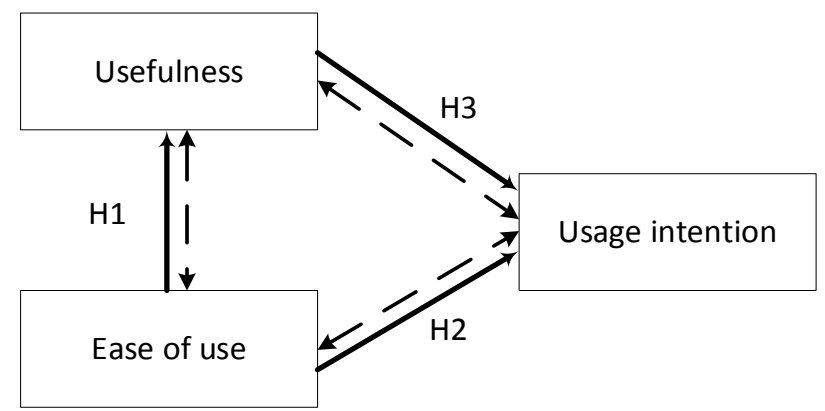

Figure 2: A hypothetical model for assessing user attitudes towards automatic ATM services in the future

A hypothetical research model was formed using the explained hypotheses and theoretical framework as sis shown in Figure 2. In order to test the hypotheses, a survey was conducted on the target sample. A research questionnaire was developed according to the hypothetical TAM model and based on theoretical research into introducing new information technology services [1]. This included research on the ability to purchase tickets for the metro via a mobile phone [4], possible impacts on the adoption of Internet banking [7], research on the impact of usefulness, ease of use and satisfaction with the intention to shop online [26] and the adoption of self-service technologies in the banking sector [32]. The questions in the questionnaire were designed as an improved combination of questionnaires used by the abovementioned papers, and selected as flagship research into the attitudes of respondents towards automatic deposit services, i.e. simplicity and usefulness. The questionnaire contains twenty-two questions in three logical sections.

After the survey was conducted, the results had to be analyze and interpreted. The first step required applying descriptive statistics to simplify the huge amount of data and display it in a more transparent and understandable way for decision makers. The next step was testing the reliability of measurement scale, which was carried out using one of the most popular methods - Cronbach's alpha coefficient. Cronbach's alfa exceeded 0.9 for the case of all three predefined constructs, where a coefficient of 0.8 or greater is considered acceptable for the relevant research.

The following step was to test usage intention of the automatic deposit service by examining the correlation between the set of constructs. For this purpose, a correlation analysis was conducted using the Pearson coefficient.

Besides correlation analysis, regression analysis was performed to estimate how much a dependent variable changes in response to a change in an independent variable [28]. Multiple regression allows consideration of the effect of two or more independent variables on an independent variable [5].

In line with these steps, decision makers can determine user attitudes towards future use of automatic deposit services. 


\subsection{Determining the optimal service implementation location}

Once the assessment of user attitudes towards using ATM automatic deposit services has been done, the question relating to the optimal ATM site remains, given that the location is crucial in determining whether the ATM will fulfil its role or not, i.e. used for transactions or not. Increasing the return on investment in automatic deposit services depends on the choice of location where the ATM is to be installed. Since the ATMs were initially placed indoor on branch premises, various studies conducted to ascertain the best possible location for opening a new branch $[18,17,11,8]$. Aldajani and Alfares [3], who also suggest determining the optimal number and position of ATMs, have proposed application of a heuristic algorithm. However, according to the same authors, this seems rather complex for managers to use practically.

In this paper, the Analytic Hierarchy Process (AHP) [20] was used to determine an appropriate location. The AHP method has already been used in different ways within the banking sector $[21,18]$ including selecting bank locations.

Formulating the AHP model required defining objectives, criteria, subcriteria and alternatives. The goal of this model is to rank potential sites for ATM positions, from the best to the worst locations based on predefined criteria.

Based on the author's long experience in working with ATMs as a bank employee and his responsibility for supporting and maintaining an ATM network, as well as his expert knowledge and available literature on determining locations for new branches [17, 18], three sets of technical, socio-economic and competition criteria were evaluated. In all, there were 12 sub-criteria.

Technical criteria:

- ATM placement - The ATM is placed indoors (of branch premises) or outdoors.

- Infrastructure - Each ATM device requires a constant power source and a permanent connection with the parent bank, and a data line with specifications to ensure connectivity. This is achieved using data cables or via a GSM connection. A line should also be provided for the alarm. Finally, the ATM is to be physically installed. The installation depends on whether it is installed in a wall, glass pane, hallways or outdoors, which requires anchoring to prevent physical removal of the ATM. All these prerequisites must be fulfilled prior to putting an ATM into operation.

- Access - This relates to technical criteria determining choice of location, and takes into account whether the respective location is close to major roads, a public transportation system, and whether car parking is available. 
- ARM visibility - This refers to the proper labelling of an ATM which is important. If potential customers are not aware that an ATM is nearby, it will not fulfil its purpose.

- Time availability - The ATM's basic purpose is that it be available to customers $24 / 7$, i.e. 24 hours a day, seven days a week. In most cases, this goal is achieved. However, ATMs located inside shopping malls, hospitals and the like, are not open $24 / 7$ as neither are the premises they are located on. Nevertheless, such sites are no less important because ATMs there are unavailable only during the night when the need for such services is minimal.

Socioeconomic criteria:

- Population - This criterion relates to the number of residents gravitating towards the ATM location. The greater the number of inhabitants in the micro-area of the ATM, the greater the possibility the AMT will be used. In evaluating this criterion, the population of Split segmented into districts was used.

- Number of legal entities nearby - Besides the employees of these legal entities who are potential customers, a geographical density of entities ensures a certain fluctuation of people visiting them, they too are potential users of ATM services.

- Fluctuation of people - The fluctuation of people in a given area is one of the socioeconomic criteria. The greater the fluctuation, the greater the chance that someone will withdraw cash or GSM vouchers, seek account information or some other ATM service.

- Degree of urbanization - This sub-criterion indicates whether the location is a city, suburb or rural settlement.

- Need for cash - The need for cash criterion in a particular location depends primarily on the type of commercial amenities in the area, i.e. retail outlets. In Croatia, cash payments are still the most common form of payment, especially for smaller amounts.

Competition criteria is divided into the following:

- ATMs of the same bank in an area - Under this sub-criterion, the physical distance from other ATMs of the same bank is considered since only with good planning can larger areas can be covered with fewer ATMs, thereby reducing costs.

- ATMs of competing banks in an area - This sub-criterion refers to the physical distance of the competing ATMs. If there is a lack of ATMs in an area, prospective customers are 'forced' to use ATM services of competing financial institutions, and customers may incur additional costs if not using their bank, which is certainly not desirable for neither the client nor their bank. 
The result of this step are ordered and prioritized (alternative) locations based on the above criteria.

\subsection{Cost-benefit analysis of using automatic deposit services}

To justify financial investments for introducing new services, a financial analysis, i.e. a cost-benefit analysis, was performed for comparing revenue and cost of the project.

The costs to implement and maintain ATMs were based on particular realsystem indicators. Allowing the cost-benefit analysis to draw on revenue and cost data, the cost-effectiveness of the investment and along with certain financial indicators describing the financial performance of introducing automatic deposit services were calculated.

Revenue from ATM services:

- Revenue from transactions executed by users whose cards were issued by the bank that also owns the ATM (ON U.S. Transaction).

- Revenue from transactions executed by users whose cards were not issued by the bank that owns the ATM (NOT ON U.S. Transactions)

- Implementation of an ATM automatic deposit service provides another source of income in the form of savings achieved avoiding the use of branches of financial institutions.

Typical costs incurred in operating the ATMs cover:

- Investing in ATMs providing automatic deposit services;

- The physical installation

- SW upgrades for ATMs

- SW upgrades for card processors

- Maintaining ATM SW and HW

- Maintaining card processors

- Power supply, host, UPS battery

- Managing the card processors

- Managing the ATMs and cost of insurance

- Communication and equipment

- Credit card companies (Visa, Amex, MasterCard)

- Other costs (data encryptions) 


\section{Implementation of methods: the case of ATMs in the City of Split}

\subsection{Assessment of user attitudes on using automatic deposit services}

It has already mentioned that over $90 \%$ of all deposits are made over the counter of branches of financial institutions. In year 2010, out of the total number of deposits, $40.02 \%$ were personal, while $59.98 \%$ were corporate deposits, which can be seen in Table 1. It is evident that target users for automated deposits are both physical and corporate subjects.

\begin{tabular}{|cccccc|}
\hline Year & Private deposits & $\%$ & Corporal deposits & $\%$ & Total \\
\hline 2006 & $7,625,615$ & $47.90 \%$ & $8,294,297$ & $52.10 \%$ & $15,919,912$ \\
2007 & $7,385,428$ & $43.78 \%$ & $9,482,673$ & $56.22 \%$ & $16,868,101$ \\
2008 & $7,191,278$ & $40.75 \%$ & $10,455,782$ & $59.25 \%$ & $17,647,060$ \\
2009 & $6,892,611$ & $37.80 \%$ & $11,341,012$ & $62.20 \%$ & $18,233,623$ \\
2010 & $7,178,218$ & $40.02 \%$ & $10,757,798$ & $59.98 \%$ & $17,936,016$ \\
\hline
\end{tabular}

Table 1: Number of private and corporate deposits on the counters of branches of financial institutions

Evaluation of ATM automatic deposit services was conducted on a sample of 900 respondents. The respondents were randomly selected via e-mail and fieldwork for the study. The research was conducted during the months of July, August and September 2011. The Pearson correlation coefficient was used to test the defined hypotheses. Variables used to test the hypotheses were average values determined from the survey, which was conducted for each of the 3 groups of questions that evaluated automatic deposit services. The variables are AJK (average ease of use), AK (average usefulness) and ANK (average usage intention)

First hypothesis: H1 - Ease of use is positively correlated to the usefulness.

The Pearson correlation was $\mathrm{r}=0.567$. The correlation between the examined variables was considered significant, and the correlation power was medium. The coefficient of determination $\mathrm{R}$ was 0.3215 .

$\checkmark$ Second hypothesis: H2 - Ease of use is positively correlated to the usage intention.

The Pearson coefficient was $\mathrm{r}=0.536$. The correlation between the examined variables was considered significant, and the correlation power was medium. The coefficient of determination $\mathrm{R}$ was 0.2877 .

$\checkmark$ Third hypothesis: H3 - Usefulness is positively correlated with the usage intention. 
The Pearson coefficient was $\mathrm{r}=0.615$. The correlation between examined variables was considered significant, and the correlation power was strong. The coefficient of determination $\mathrm{R}$ was 0.3783 .

The results suggest that for the future intention of using the automatic deposit service, the most important factor is usefulness, followed by the very simplicity of the service.

The behavior of the independent variables (average ease of use and average usefulness) in terms of the criterion variable (usage intention) was determined by conducting multiple regression analysis on the results of the questionnaire once correlation analysis confirmed the correlation between individual constructs on usage intention of the automatic deposit service.

The multiple regression coefficient $\mathrm{R}=0.656$ indicates a strong degree of correlation, with the coefficient of determination $\mathrm{R}^{\wedge} 2$ equivalent to 0.430 . In this case, the independent variables explained $43 \%$ of the dependent variable.

Moreover, the predictor variables predicted significantly the criterion variable where $\mathrm{F}(2.208)=78.529$, and $\mathrm{p}<.005$, meaning that the regression model represented the data quite well. The form of multiple regression equation is $\mathrm{ANK}=0.312+0.559+0.424 * \mathrm{AK} * \mathrm{AJK}$.

Also worth mentioning is that the AJK and AK coefficients were significantly different from 0 given that $\mathrm{p}=0.000$, which is less than 0.05 . Accordingly, the higher the ease of use, the greater the usage intention. The same applied for usefulness of the service.

\subsection{Determining the optimal service location}

The most popular recently used multiple criteria method is the Analytic Hierarchy Process (AHP method). One of the main reasons this is so is its flexibility and ability to adapt to the majority of those using the software package ExpertChoice. The method was developed by Thomas Saaty in 1970. Solving complex decision-making problems using this method requires dismantling the following components [21]:

- Goal

- Criteria and sub-criteria

- Alternatives

For the purpose of this paper, ATMs previously installed in 39 locations in Split and operating were considered as alternatives. Each of the alternatives was evaluated using expert knowledge on each criterion and sub-criterion. Evaluation of sub-criterion alternatives is shown in Figure 3. 


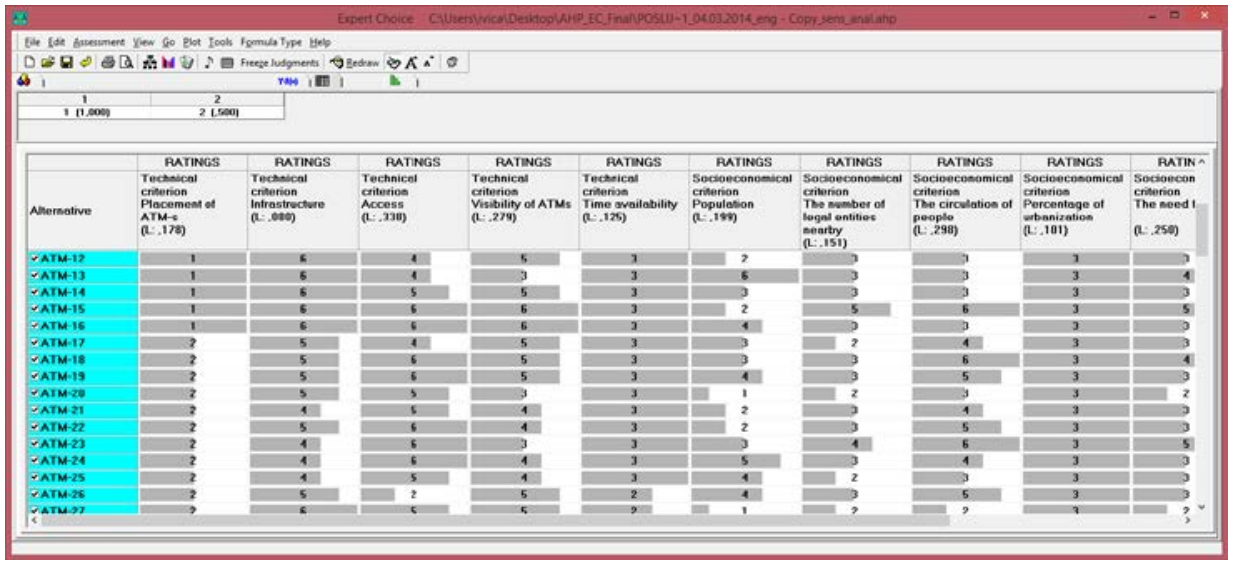

Figure 3: Data grid showing evaluation of sub-criterion alternatives

The AHP method determined the attractiveness of the existing location. The software package ExpertChoice software was used to develop the AHP. The weight assigned to the sub-criterion level and the priorities for each sub-criterion relative to the alternatives are shown in Figure 4.

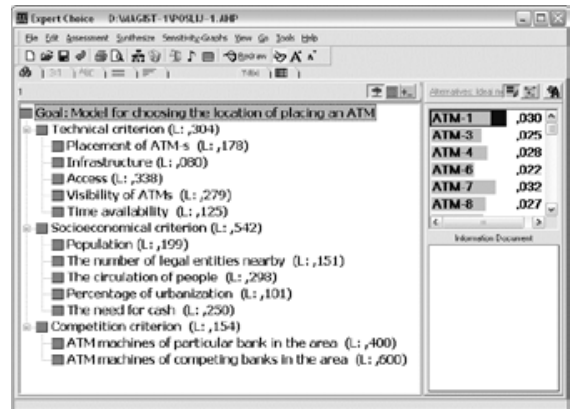

Figure 4: Goal, criteria, sub-criteria and alternatives in the ModelView window of ExpertChoice

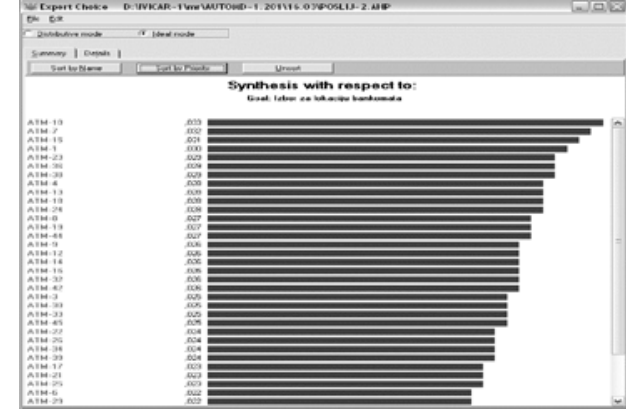

Figure 5: Total priorities of the alternatives after performing synthesis according to the primary goal set

The interesting thing about these first five locations is that the first four locations are where the ATMs were installed indoors (inside of branch premises), thus contributing to such a high result, while the ATM on Location 23 was installed outdoors (outside the branch premises).

The results provided by the software tool ExpertChoice 2000 are also shown in the sensitivity analysis. The analysis performed to see how possible changes in input data affect output results. Changing the weight of one criterion using the performance option in the sensitivity analysis tool caused other criteria weights to change in proportion to the initial weight. The left side of Figure 6 shows the shares of certain sub-criterion while on the right there are alternatives for initial weight criterion. As can be seen, the best alternative is 
ATM-10 followed by locations ATM-23, ATM-15, ATM-1 whereas the worst location is ATM-7.

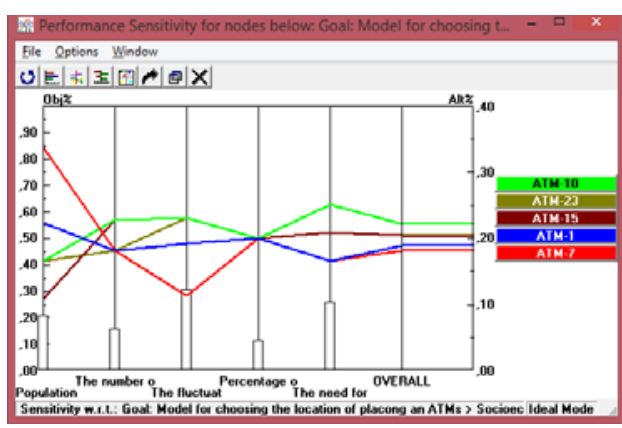

Figure 6: Sensitivity analysis performance option: initial state

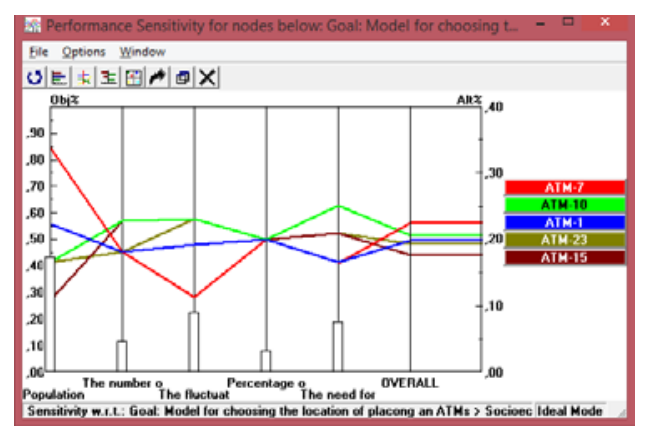

Figure 7: Sensitivity analysis performance option: state after changes to one criterion (Population)

If the population criterion increases from the initial $20 \%$ to $44 \%$, the alternative location ATM-7 becomes the best location followed by location ATM-10. Other alternatives also experience location changes, as shown in Figure 7.

Changes to the value of one criterion or sub-criterion can significantly change relations at the same level of the hierarchical structure, thus different what-if scenarios can be visually displayed along with the impacts of criterion or sub-criterion changes to the ultimate goal.

\subsection{Cost benefit analysis of using the automatic deposit service}

Of the 10 locations, 6 were located inside the branch, and four were located externally.

Properly calculating cost effectiveness required taking into consideration the fact that that particular financial institutions had a dominant role relative to other financial institutions. Therefore, this led to an increase in the number of transactions at ATMs from 50 to 70 transactions per ATM per day with the percentage of ON-US transactions increasing to $90 \%$ of the total number of transactions. Furthermore, the number of deposit transactions increased from 4 to 8 in the first year of service introducing the service. 


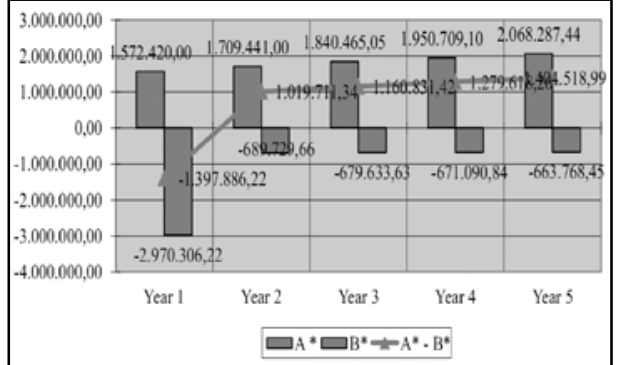

Figure 8: $C B A$ diagram

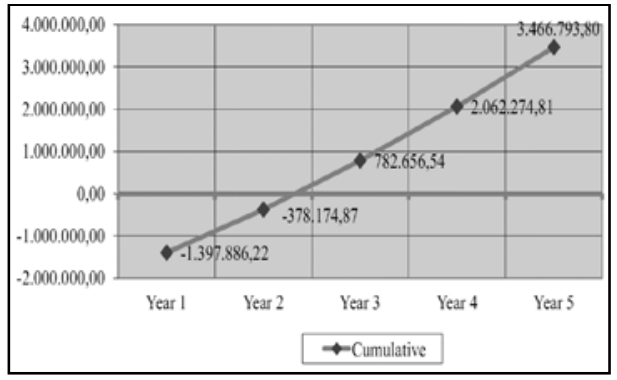

Figure 9: Cumulative investment

The CBA diagram is shown above in Figure 8. When considering the cumulative approach (Figure 9), a return on investment of HRK 800,000 can be expected in the third year. The investment in the ATM automatic deposit service begins to make money after two years of use, and hypothetically could reach as much as HRK 3.5 million after five years.

\section{Conclusion}

Implementation of the TAM model provides answers on the usefulness of and ease of use of automated deposit services from the perspective of potential users. The results assist decision makers in predicting more easily the future acceptance of an automatic deposit service.

The next important issue to consider is choosing the right locations for installing the ATMs. An optimal location selection was carried out using the multi-criteria AHP method which itself is based on established criteria (3) and sub-criteria (12).

After performing the two previous steps, the viability of the investment in automatic deposit service of the ATMs was evaluated.

To facilitate implementation of the methods proposed in the paper, a case study was presented with a complete statistical, multicriterial and financial analysis.

Based on the previous steps, the authors defined procedures that financial institutions can use to make relevant decisions based on evaluations of user attitudes, optimal site selection and economic cost effectiveness of the implemented ATM automatic deposit services as opposed to traditional deposit services.

\section{References}

[1] Ajzen, I. (1991). Theory of planned behavior. Organizational Behavior and Human Decision Processes, 50(2), 179-211. 
[2] Al-Gahtani, S. (2011). Modeling the electronic transactions acceptance using an extended technology acceptance model. Applied Computing and Informatics, 9, 4777. doi:10.1016/j.aci.2009.04.001.

[3] Aldajani, M.A., Alfares, H.K. (2009). Location of banking automatic teller machines based on convolution, King Fahd University of Petroleum and Minerals. Computers and Industrial Engineering, 57(4), 1194-1201. doi:10.1016/j.cie.2009.05.013.

[4] Babaee, N. (2010). Investigating Effective Factors and Presenting a Practical Guideline to Adoption of Mobile Ticketing. Lulea University of Technology.

[5] Skyes, A. (1992). An introduction to regression analysis. Coase Lecture, Law School, Working Paper, Chicago.

[6] Bandura, A. (1982). Self-efficacy mechanism in human agency. American Psychologist, 37(2), 122-147. doi:10.1037/0003-066x.37.2.122.

[7] Baraghani, S. N. (2009). Factors Influencing the Adoption of Internet in Banking. Lulea University of Technology.

[8] Boufounou, P.V. (1995). Evaluating bank branch location and performance: A case study. European Journal of Operational Research, 87(2), 389-402. doi:10.1016/03772217(92)00080-5.

[9] Cheng, T. E., Lam, D. Y. \& Yeung, A. C. (2006). Adoption of internet banking: An empirical study in Hong Kong. Decision Support Systems, 42(3), 1558-1572. doi:10.1016/j.dss.2006.01.002.

[10] Chuttur, M. Y. (2009). Overview of the technology acceptance model: Origins. Developments and Future Directions, 9, 9-37.

[11] Cornuejols, G., Fisher, M.L., Nemhauser, G.L. (1977). Location of bank accounts to optimize float: an analytical study of exact and approximate algorithms. Management Science, 23, 789-810.

[12] Davis, F. (1989). Perceived usefulness, perceived ease of use, and user acceptance of information technology. MIS Quarterly, 13 (3), 319-340. doi:10.2307/249008.

[13] Diebold. (2010). Deposit Automation, Diebold. http://www . atmmarketplace.com/whitepapers/diebolds-deposit-automationsolution-bethpage [Accessed on 20 September 2014].

[14] Diebold. (2009). Deposit Automation: Benefits without the hassle, Diebold. http://www.ibat.org/files/PDFs/Diebold.pdf [Accessed on 20 September 2014].

[15] Dulčić, Ž, Pavlić, D., Silić, I. (2012). Evaluating the intended use of decision support system (DSS) by applying technology acceptance model (TAM) in business organizations in Croatia, Procedia - Social and Behavioral Sciences, 58, 1565-1575. doi:10.1016/j.sbspro.2012.09.1143.

[16] ESTA Annual Conference. (2009). Deposit automation and other ATM market trends, Rome. http://Www.esta-cash.eu/documents/romedocuments/II.4.Hirsch.pdf [Accessed on 20 September 2014].

[17] Ferreira, F.F., Santos, S.P., Rodrigues, P.M.M. (2009). Adding value to bank branches' performance evaluation using cognitive maps and MCDA: a case study. Journal of the Operations Research Society, 62(7), 1320-1333. doi:10.1057/jors.2010.111.

[18] Ferreira, F.F., Spahr, R.W., Santos, S.P., Rodrigues, P.M.M. (2010). A multiple criteria framework to evaluate bank branches potential attractiveness, Banco de Portugal, Working Paper 10, Portugal. 
[19] Fishbein, M. \& Ajzen, I. (1975). Belief, Attitude, Intention, and Behavior: An Introduction to Theory and Research. Reading, MA: Addison-Wesley.

[20] Forman, Ernest H., with Gass, Saul I. (2011). The analytic hierarchy process - an exposition. Operations Research, 49(4), 469-486. doi:10.1287/opre.49.4.469.11231.

[21] Hunjak, T, Jakovčević, D. (2001). AHP based model for bank performance evaluating and rating, ISHAP, 6, 149-158.

[22] Lee, M.C. (2009). Factors influencing the adoption of internet banking: An integration of TAM and TPB with perceived risk and perceived benefit. Electronic Commerce Research and Applications, 8(3), 130-141. doi:10.1016/j.elerap.2008.11.006.

[23] Luarn, P. \& Lin, H.H. (2005). Toward an understanding of the behavioral intention to use mobile banking, Computers in Human Behavior, 21(6), 873-891. doi:10.1016/j.chb.2004.03.003.

[24] Money, W. and Turner, A. (2010). Application of the technology acceptance model to a knowledge management system. System Sciences, 1, 1-19.

[25] NCR. (2009) Goodbye envelopes! NCR deploys 10000. Intelligent Deposit ATM in U.S., NCR. www.ncr.com [Accessed on 20 September 2014].

[26] Ramayah, T, Joshua Ignatius, J. (2009). Impact of perceived usefulness, perceived ease of use and perceived enjoyment on intention to shop online. School of Management, Universiti Sains Malaysia, Working Paper, Malaysia.

[27] RBR. (2006). ATM-market growth soars in Central Eastern Europe, RBR. http: / / wwW. openconsultgroup. com/docs / ATM\%20News. doc ? id=8990\&prc $=32 \& p a g e=68$ [Accessed on 20 September 2014].

[28] Rigopoulos, G., Askounis, D. (2007). A TAM framework to evaluate users' perception towards online electronic payments. Journal of Internet Banking and Commerce, 12(3), 1-6. 